\title{
Hot-Pressing of $(\mathrm{Ti}, \mathrm{Mt})(\mathrm{C}, \mathrm{N})-\mathrm{Co}-\mathrm{Mo}_{2} \mathrm{C} \quad(\mathrm{Mt}=\mathrm{Ta}, \mathrm{Nb})$ powdered
}

\section{cermets synthesized by a mechanically induced self-sustaining reaction}

\author{
E. Chicardi ${ }^{1,2 *}$, F. J. Gotor ${ }^{2}$, V. Medri ${ }^{3}$, S. Guicciardi ${ }^{3}$, S.Lascano ${ }^{4}$ and J. M. Córdoba ${ }^{2,5}$ \\ ${ }^{1}$ Departamento de Ingeniería Metalúrgica y Materiales, Universidad Técnica Federico Santa \\ María, Av. España 1680, Valparaíso, Chile. \\ ${ }^{2}$ Instituto de Ciencia de Materiales de Sevilla, Centro Mixto CSIC-US, 41092 Sevilla, Spain. \\ ${ }^{3}$ Institute of Science and Technology for Ceramics (CNR), 48018 Faenza, Italy. \\ ${ }^{4}$ Departamento de Ingeniería Mecánica, Universidad Técnica Federico Santa María, Av. España \\ 1680, Valparaíso, Chile. \\ ${ }^{5}$ Departamento de Química Inorgánica, Universidad de Sevilla, 41012 Sevilla, Spain
}

\begin{abstract}
A mechanically induced self-sustaining reaction (MSR) has been successfully employed for manufacturing powdered cermets based on $\mathrm{Ti}$, $\mathrm{Ti}-\mathrm{Ta}$ and $\mathrm{Ti}-\mathrm{Nb}$ carbonitrides using $\mathrm{Co}$ as the binder phase and $\mathrm{Mo}_{2} \mathrm{C}$ as the sintering additive. The powders were sintered by hot-pressing, and complete chemical, microstructural and mechanical characterizations were performed on the densified cermets. When elemental $\mathrm{Ta}, \mathrm{Nb}$ and/or $\mathrm{Mo}_{2} \mathrm{C}$ were added to the initial raw mixture submitted to the MSR process, smaller ceramic grains were observed after sintering, which suggested that ceramic particle growth was hindered by the presence of $\mathrm{Ta}, \mathrm{Nb}$ and/or Mo in the host titanium carbonitride structure. Nanoindentation measurements enabled the determination of the hardness of the ceramic and binder phases, and values in the range of 26-29 GPa and 14$16 \mathrm{GPa}$ were found, respectively. The high hardness values of the binder were related to the formation of intermetallic phases.
\end{abstract}


Keywords: Mechanical milling; Cermets; Hot-Pressing; Mechanical properties; Nanohardness; Titanium carbonitride.

\section{Introduction}

The use of ceramics as structural components is often limited by the brittleness of these materials. The addition of second phase inclusions to hinder the propagation of cracks and the choice of ductile metallic phases for reinforcing the ceramic matrix are some of the most studied approaches to overcome such a disadvantage. Among the ceramic-metal composite materials, titanium carbonitride-based cermets have drawn great attention to replace the traditional WC-Co hardmetals. Despite their lower bending strength, cermets have properties such as good wear, oxidation resistance and high mechanical strength at high temperature [1-3], which make cermets well adapted to the requirements of specific machining processes such as high-speed finishing. Moreover, another advantage over hardmetals is the possibility of introducing other transition metals, usually as secondary carbides $\left(\mathrm{TaC}, \mathrm{NbC}\right.$ or $\left.\mathrm{Mo}_{2} \mathrm{C}\right)$, which are completely or partially soluble into the titanium carbonitride structure, thereby allowing the properties of the cermets to be tailored [4].

Two major problems that restrict the wider use of cermets are poor interfacial cohesion between the metallic phase and the ceramic particles and the frequent occurrence of large particle size distributions. To overcome such unfavorable features, a reduction in the mean ceramic particle size to the nanometer region has been recently proposed [5], although choosing the appropriate ductile phase, synthetic path and processing method employed is also extremely important [6]. 
A mechanically induced self-sustaining reaction (MSR) has been proven to be an attractive and affordable alternative to the conventional methods for producing advanced ceramics [7-9], ceramic matrix composites [10-12], ceramic-metal composites [13-15] and intermetallic compounds [16-18]. An MSR is a simple and low-energy-cost procedure that produces fine and homogeneous powders. This method, similar to selfpropagating high-temperature synthesis (SHS) [19, 20], uses the strong exothermic character of the reactant powder mixtures to promote self-sustaining reactions induced by the mechanical energy supplied by high-energy ball mills [21]. It has been shown that the MSR technique allows obtaining complex solid solutions in a consistent and direct manner, with a high control of the chemical composition and microstructure $[12, \underline{16,22]}$. More precisely, homogeneous titanium-based carbonitride solid solutions have already been synthesized and successfully employed in the fabrication of cermets [14, 23].

Alternatively, hot-pressing (HP) has been widely used for sintering and developing different materials [24, 25], including composite materials, such as hardmetals and cermets $[26,27]$. This method allows obtaining materials with higher densification, a more uniform fine-grained microstructure, improved physical and mechanical properties and high reliability compared to conventional processes [28].

A study of an MSR coupled to an advanced sintering technique, spark plasma sintering (SPS), has been previously reported [29]. In this work, the experimental procedure of coupling the MSR and HP techniques to fabricate titanium carbonitridebased cermets was examined. The microstructural and mechanical properties of Ti, Ti-Ta and $\mathrm{Ti}-\mathrm{Nb}$ carbonitride cermets with $\mathrm{Co}$ as the binder phase, synthesized first by MSRs and subsequently consolidated by HP, were characterized and examined as a function of 
the experimental conditions employed. The effect of the sintering process on the densification behavior, the final cermet chemical composition and the particle size distribution were systematically studied.

\section{Materials and Methods}

Ti powder (99\% purity, < 325 mesh, Strem Chemicals, major impurities: O (2500 ppm) and $\mathrm{Cl}(400 \mathrm{ppm}))$, Ta powder (99.6\% purity, < 325 mesh, Alfa Aesar), Nb powder (99.6\% purity, < 325 mesh, Alfa Aesar), $\mathrm{Mo}_{2} \mathrm{C}$ powder (99\% purity, < 325 mesh, Strem Chemicals), graphite powder $(<270$ mesh, $\mathrm{Fe} \leq 0.4 \%$, Merck $)$ and Co powder $(99.8 \%$ purity, < 100 mesh, Strem Chemicals) were used as raw materials in this study. Powder mixtures with different atomic/molar ratios according to the nominal compositions expressed in table 1 were subjected to high-energy ball milling to synthesize the powdered cermets via MSRs following a previously published procedure [30]. Briefly, $46.5 \mathrm{~g}$ of the powder mixtures together with 13 tempered steel balls $(\mathrm{d}=20 \mathrm{~mm}, \mathrm{~m}=$ $32.6 \mathrm{~g})$ were put into a tempered steel vial (300 $\mathrm{ml}$ in volume) and milled using a modified planetary ball mill (P4, Fritsch) at a spinning rate of $400 \mathrm{rpm}$ under 6 atm of reactive $\mathrm{N}_{2}$ gas $\left(\mathrm{H}_{2} \mathrm{O}\right.$ and $\mathrm{O}_{2}<3 \mathrm{ppm}$, Air Liquide). The planetary ball mill enabled monitoring of the MSRs by continuously measuring the pressure inside the vial. When the MSR associated with the synthesis of the carbonitride phase takes place, the temperature increases due to the release of heat from the exothermic reaction, which consequently increases the total pressure. This moment, known as the ignition time and defined as the critical milling time required to induce the MSR process, can thus be 
determined from the spike in the recorded time-pressure data. After ignition, the milling was continued to ensure full conversion and homogenization.

The powdered cermets were then placed into a hardened stainless steel die with an internal diameter of $45 \mathrm{~mm}$ and pressed at 10 tons for $5 \mathrm{~min}$. The green bodies were subsequently subjected to HP in an induction-heated graphite die at various temperatures between $1300^{\circ} \mathrm{C}$ and $1360^{\circ} \mathrm{C}$ (heating rate of $20^{\circ} \mathrm{C} / \mathrm{min}$ and free cooling) with holding times from 3 to $8 \mathrm{~min}$. The sintering temperatures were selected based on the transition metal composition of the cermets. For higher refractory metals, higher sintering temperatures were used, similar to previous studies $[13,30,31]$. The dwell time used for each cermet was the minimum time necessary to reach maximum shrinkage (densification) at the sintering temperature. A low vacuum of $\sim 100 \mathrm{~Pa}$ and an applied pressure of $20 \mathrm{MPa}$ were always used (table 1).

X-ray diffraction diagrams of the powdered cermets and polished surfaces of the sintered cermets were obtained with a Panalytical X'Pert Pro instrument equipped with a

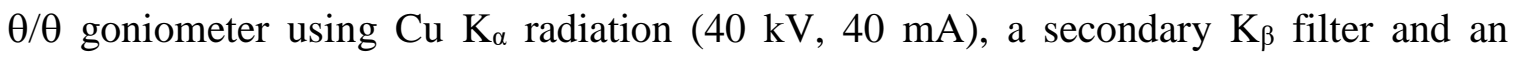
$\mathrm{X}^{\prime}$ Celerator detector. The diffraction patterns were scanned from $30^{\circ}$ to $140^{\circ}(2 \theta)$ at a scanning rate of $0.42^{\circ} \mathrm{min}^{-1}$. The lattice parameters were calculated from the entire set of peaks in the XRD diagrams using the Fullprof computer program assuming suitable symmetry for all the observed phases.

Scanning electron microscopy (SEM) images were acquired with a Hitachi FEG S4800 microscope in an electron secondary mode. The cermets were sectioned and polished for the SEM observation and microhardness measurements. The transition metal contents in the ceramic and binder phases were measured using energy dispersive X-ray 
spectrometry (XEDS) coupled to the SEM microscope. Image analysis (IA) with the Image-Pro Plus 6.2 software was employed to obtain the ceramic particle size distribution from the SEM micrographs using the linear intercept method [32]. Five SEM micrographs at magnifications between 1000x and 5000x were used per each cermet composition.

Vickers hardness tests were performed at room temperature in a microhardness FM-700 instrument (Future-Tech. Corp) at a load of $9.81 \mathrm{~N}$ (1 kgf) for $15 \mathrm{~s}$. Twelve microindentations were taken at different locations on the polished cermet, and the reported value was the average of the different measurements. The fracture toughness ( $\left.\mathrm{K}_{\mathrm{IC}}\right)$ was determined using the indentation microfracture (IM) method with the crack length produced at the corners of the Vickers indentations and the equation of Niihara et al [33]. This method allows obtaining $\mathrm{K}_{\mathrm{IC}}$ values in hardmetals and cermets with maximum deviations of $20 \%$ compared with the most commonly used single-edgenotched-beam (SENB) tests [34]. The load used was enough to produce cracks with at least half the length of the indentation diagonal, which is the minimum length required to obtain $\mathrm{K}_{\mathrm{IC}}$ values independent of the load [35]. The accurate measurement of the surface length of the arrested cracks was performed by SEM inspection.

The dynamic Young's modulus (E), shear modulus $(\mathrm{G})$ and Poisson's ratio $(v)$ were measured using the non-destructive resonance frequency method [36] on $28 \times 8 \times 0.8 \mathrm{~mm}^{3}$ specimens using a Hewlett-Packard gain-phase analyzer. Five specimens were tested for each cermet composition.

The flexural strength $(\sigma)$ was determined at room temperature using a semiarticulated silicon carbide four-point fixture with a lower span of $20 \mathrm{~mm}$ and an upper 
span of $10 \mathrm{~mm}$ with a screw-driven load frame (Instron mod. 6025, according to the ASTM norm no. ASTM C1161-13. Five chamfered bars $\left(25 \times 2.5 \times 2 \mathrm{~mm}^{3}\right)$ of each cermet were tested and loaded with a crosshead speed of $0.05 \mathrm{~mm} / \mathrm{min}$.

The nanoindentation tests were performed on the polished surfaces of cermets using a commercial nanoindenter (Nano Indenter XPTM, MTS Systems Corporation) fitted with a Berkovich diamond tip. A total of 400 indentations (grid of $20 \times 20$ indentations) at a peak load of $5 \mathrm{mN}$ were made on each cermet. The indenter was continuously loaded up to the peak load in $15 \mathrm{~s}$ and immediately unloaded without a holding time. The nanohardness and Young's modulus were calculated using the data acquisition software of the nanoindenter (TestWorksTM ver. 4.06A), which is based on the Oliver and Pharr's model [37]. The raw load-displacement data were automatically corrected by the software for the machine compliance and thermal drift. The area function of the indenter tip was calibrated using a standard fused silica specimen before testing.

\section{Results and Discussion}

\subsection{Synthesis, microstructure and chemical composition.}

After 40-45 min of milling treatment in the planetary mill, a pressure spike was observed in the time-pressure record for all the different powder mixtures (table 1) due to the occurrence of a highly exothermic reaction inside the vial, i.e., the MSR process, associated with the ignition of the self-sustaining reaction that led to the instant formation

of the carbonitride ceramic phase, as later confirmed by XRD measurements. The milling was continued for $30 \mathrm{~min}$ after ignition (post-combustion milling time) to ensure the completion of the reaction and to obtain a narrow particle size distribution, which is 
required to achieve an optimal cermet densification after sintering. A total milling time of approximately 70-75 min was employed for the synthesis of the powdered cermets.

The XRD diagrams of the powdered cermets after the MSR synthesis are shown in figure 1a, in which the ceramic phases composed of transition metal carbonitrides, $(\mathrm{Ti}$, $\mathrm{Mt})(\mathrm{C}, \mathrm{N})(\mathrm{Mt}=\mathrm{No}$ element, $\mathrm{Nb}$ or $\mathrm{Ta})$, can be identified. The assignment of the reflections of the ceramic phases was carried out by comparing the experimental XRD patterns with the following reference patterns present in the PDF-2 database (ICCD): TiN (38-1420), TiC (32-1383), TaN (49-1283), TaC (35-0801), NbN (38-1155) and $\mathrm{NbC}$ (38-1364). The Fm-3m space group for the carbonitride phases was confirmed by indexing with DICVOL06 software.

The formation of solid solution carbonitrides from elemental powder mixtures via an MSR under a $\mathrm{N}_{2}$ atmosphere and dry high-energy ball milling conditions has already been demonstrated [38]. Mechanistically, during the first stage of milling, previous to the ignition time, the amorphization of graphite together with the intimate contact between $\mathrm{Ti}, \mathrm{Nb}, \mathrm{Ta}$ and graphite takes place, leading to the uniform distribution of graphite on the surface of the deformed $\mathrm{Ti}, \mathrm{Nb}, \mathrm{Ta}$ and/or alloy particles [39]. During this time, the mechanical energy transferred to the powders also creates particle refinement and the accumulation of lattice defects, which appear to favor the combustion reaction [40]. When the powder mixture is sufficiently activated at a certain milling time, the $40-45 \mathrm{~min}$ previously mentioned, the subsequent ball impacts induce the combustion reaction, which suddenly transforms the reactant powder mixture in the $(\mathrm{Ti}, \mathrm{Mt})(\mathrm{C}, \mathrm{N})(\mathrm{Mt}=\mathrm{Ta}, \mathrm{Nb})$ carbonitride phase. The self-propagating process is also favored by the reactive $\mathrm{N}_{2}$ atmosphere as the exothermicity of the global reaction is increased [40]. 
Notably, adding to the initial powder mixture up to $25 \mathrm{wt} \%$ of phases (Co as a binder and $\mathrm{Mo}_{2} \mathrm{C}$ as an additive) that do not participate in the MSR process did not inhibit the formation of the carbonitride phase via the combustion reaction. However, the reflections of $\mathrm{Co}$, the presumed binder phase, were not observed in figure 1a after the MSR process. Instead, a broad peak centered at $\sim 43^{\circ} 2 \theta$ was seen in all of the XRD diagrams, which as published previously [31], corresponds to an alloy containing Co and the other transition metals ( $\mathrm{Ti}, \mathrm{Nb}$ and $\mathrm{Ta}$ ) introduced in the starting powder mixture. This alloy was formed during the MSR process as consequence of the significant heat released by the highly exothermic reaction of the carbonitride formation, which locally increased the temperature of the powder mixture and caused the melting of Co and the dissolution into this molten phase of some of the $\mathrm{Ti}, \mathrm{Nb}$ and/or Ta metal. In addition, no evidence of $\mathrm{Mo}_{2} \mathrm{C}$ along with the cermet TiTa20Co5Mo was detected in the XRD diagram of the powdered cermet (figure 1a), probably due to the low amount (5 wt $\%$ ) together with the effect of milling in reducing the intensity of the XRD peaks.

Figure $1 \mathrm{~b}$ shows the XRD diagrams of the cermets after HP sintering. No significant variation in the $2 \theta$ position of the XRD peaks for the carbonitride phases compared with the powdered cermets was observed. This was confirmed by the similar lattice parameters determined before and after the sintering process (table 2), which clearly suggests that any variation in the composition of the carbonitride phases occurred during sintering. In contrast, differences observed in the lattice parameters of the carbonitride phases of the different cermets were the consequence of the presence of Ta or $\mathrm{Nb}$ in the host titanium carbonitride structure, which tends to enlarge the crystal lattice $[7, \underline{30]}$. 
Concerning the binder phase, it was observed that this phase was always composed of intermetallic compounds after HP sintering, as reported in previous studies of similar cermets sintered by pressureless (PS) methods $[13,30, \underline{31]}$ or spark plasma sintering (SPS) [29]. Based on the Ti-Co binary phase diagram [41] and the PDF-2 database, the detected intermetallics were cubic $\mathrm{TiCo}_{2}$ [Fd3m, 227], hexagonal $\mathrm{TiCo}_{2}$ [P63/mmc, 194] and cubic TiCo [Pm3m, 221]. In fact, as shown later according to XEDS-SEM measurements (table 2), the intermetallic phases also contained the other minor transition metals $(\mathrm{Mt}=\mathrm{Ta}, \mathrm{Nb}$ and/or $\mathrm{Mo})$ and are more precisely described as solid solutions with the general formula (Ti, Mt1, Mt2)Co2 and (Ti, Mt1, Mt2)Co. For cermets Ti20Co and TiTa10Co, only the cubic 1:1 intermetallic was observed [TiCo and (Ti, Ta)Co, respectively]. For cermets TiTa20Co and TiTa20Co5Mo, only one intermetallic compound was also observed, but the compound had a stoichiometry of 1:2. Specifically, cubic $(\mathrm{Ti}, \mathrm{Ta}) \mathrm{Co}_{2}$ and hexagonal $(\mathrm{Ti}, \mathrm{Ta}, \mathrm{Mo}) \mathrm{Co}_{2}$ were found for TiTa20Co and TiTa20Co5Mo, respectively. The introduction of Mo into the 1:2 intermetallic compound, derived from the dissolution of $\mathrm{Mo}_{2} \mathrm{C}$ in the molten binder during sintering, caused a structural modification from cubic to hexagonal. Finally, TiNb20Co showed the presence of cubic intermetallics at stoichiometries of both 1:1 and 1:2, i.e., (Ti, $\mathrm{Nb}) \mathrm{Co}$ and $(\mathrm{Ti}, \mathrm{Nb}) \mathrm{Co}_{2}$. The formation of all these different intermetallic compounds suggests the excessive dissolution of carbonitride particles in the molten binder during sintering and the incomplete carbonitride reprecipitation upon cooling. The different intermetallic compounds formed depends on the partial solubility of $\mathrm{Ti}, \mathrm{Ta}, \mathrm{Nb}$ and Mo in the molten Co-rich phase, the differing stabilities of the carbonitride solid solutions, (Ti, Mt1, $\mathrm{Mt} 2)(\mathrm{C}, \mathrm{N})$, and the initial percentage of Co $[42,43]$. 
Selected SEM images at two different magnifications showing the microstructure of the sintered cermets are presented in figures 2 and 3. An optimal densification, with practically no porosity, was observed for all the compounds except the TiTa10Co cermet (table 3). For this cermet, the reduced amount of binder was not adequate to ensure optimal spreading and penetration of the molten binder in between the ceramic particles, leading to retained porosity as confirmed by the volumetric porosity determined by image analysis of the SEM micrographs. This generally optimal densification is better than that observed in similar cermets sintered by SPS [29], in which a remnant porosity of approximately $3-4 \%$ was always detected. Moreover, no loss of molten binder was detected during the HP process, a phenomenon that was observed during SPS when the dwell time or the sintering temperature was increased [29].

Binder phase that was located inside large ceramic particles (marked with arrows) was more frequently observed in the SEM micrographs of the Ti20Co cermet (figures 2a and 3a), which is characteristic of ceramic growth by coalescence processes. During sintering, due to particle growth and when the volume fraction of ceramic particles is high, different particles can come into contact, inducing processes of coalescence and the formation of even coarser particles $[22,44]$. For the other cermets containing $\mathrm{Ta}, \mathrm{Nb}$ and/or Mo (from the added $\mathrm{Mo}_{2} \mathrm{C}$ ), coalescence was not observed as clearly. Instead, ceramic particles with a more rounded shape and sometimes with the typical core-rim microstructure were detected (marked with squares in figures $2 \mathrm{~b}-\mathrm{e}$ and $3 \mathrm{~b}-\mathrm{e}$ ), which are indicative of predominant dissolution-reprecipitation processes.

Moreover, an inhomogeneous particle size distribution was observed in the cermets, with regions of coarse ceramic particles surrounded by areas with significantly smaller 
particles. This inhomogeneous microstructure can be explained based on an inhomogeneous temperature distribution within the sample during sintering, partly due to the short dwelling time at the maximum temperature. It is also clear from figures 2 and 3 that this effect only occurred when $\mathrm{Ta}$ and $\mathrm{Nb}$ were present in the carbonitride structure (cermets TiNb20Co, TiTa20Co, TiTa10Co and TiTa20Co5Mo), which probably induce a reduction in the thermal conductivity of the system as inferred by the differing thermal conductivities of transition metal carbides and nitrides [45]. Moreover, the presence of these refractory metals in the binder phase, as shown later by XEDS-SEM measurements, may be an additional reason for the microstructural inhomogeneities because a higher sintering temperature would be necessary to ensure a homogeneous molten binder. An inhomogeneous microstructure was also found in cermets sintered by SPS [29], likely due to the same reason discussed above, a short dwell time. Applying longer dwell times in both sintering techniques would lead to not only a more homogeneous microstructure but also a significant growth of particle size, reaching a microstructure similar to cermets sintered by conventional PS methods [31].

Furthermore, despite the presence of these regions with coarse ceramic particles, the addition of $\mathrm{Ta}$ and $\mathrm{Nb}$ to the basic cermet composition, $\mathrm{Ti}(\mathrm{C}, \mathrm{N}) / \mathrm{Co}$ (corresponding to the Ti20Co cermet), had a direct effect on reducing the overall size of the ceramic particles, as illustrated in figure 4 , in which the particle size distribution obtained from the image analysis protocol is shown. The mean ceramic particle size is presented in table 3 along with other interesting microstructural parameters, such as the volumetric percentage of binder phase and porosity. Figure 4 shows how the proportion of small particles increases when $\mathrm{Ta}$ and $\mathrm{Nb}$ are present in the host titanium carbonitride structure, 
suggesting that these elements hinder the ceramic growth. Moreover, this effect was more marked in cermets TiTa10Co and TiTa20Co5Mo, in which the majority of particles (figure 4) and the mean ceramic size were in the submicrometer range (table 3). It has been extensively reported that the presence of $\mathrm{Mo}_{2} \mathrm{C}$ has a marked influence on reducing ceramic particle size in cermets [46]. Moreover, a lower Co content increases the contiguity between the ceramic particles, reducing the area of the solid/liquid interfaces where dissolution and reprecipitation take place and restricting the overall grain growth [47].

Finally, note that the volumetric percentage of the binder phase determined by image analysis was in all cases much higher than that calculated according to the rule of mixture taking into account the starting nominal composition of the cermets (table 3 ). This result is consistent with the excessive dissolution of the ceramic particles in the molten binder phase during HP sintering and the formation of the aforementioned intermetallic phases.

XEDS-SEM analyses were conducted to determine the transition metal compositions (at.\%) in the ceramic and binder phases. The results obtained and reported in table 2 confirmed the presence of $\mathrm{Ti}, \mathrm{Nb}, \mathrm{Ta}$ and/or $\mathrm{Mo}$ in the binder phase and were also in agreement with the stoichiometry of the intermetallic phases assigned using XRD (figure 1b). Specifically, a unique binder phase with 1:1 stoichiometry and a chemical formula of $\mathrm{Ti}_{0.49} \mathrm{Co}_{0.51}$ and $\left(\mathrm{Ti}_{0.45} \mathrm{Ta}_{0.04}\right) \mathrm{Co}_{0.51}$ was found in cermets $\mathbf{T i 2 0 C o}$ and TiTa10Co, respectively. For cermets TiTa20Co and TiTa20Co5Mo, intermetallic phases with a stoichiometry close to $1: 2$ and chemical formulas of $\left(\operatorname{Ti}_{0.32} \mathrm{Ta}_{0.40}\right) \mathrm{Co}_{0.64}$ and $\left(\mathrm{Ti}_{0.26} \mathrm{Ta}_{0.06} \mathrm{Mo}_{0.04}\right) \mathrm{Co}_{0.64}$ were observed, respectively. Furthermore, in the TiTa20Co5Mo 
cermet, Mo was only detected as part of the binder phase by XEDS-SEM, confirming that the added $\mathrm{Mo}_{2} \mathrm{C}$ was dissolved in the binder phase during sintering. Finally, two different binder compositions could be determined in the TiNb20Co cermet with chemical formulas of $\left(\mathrm{Ti}_{0.43} \mathrm{Nb}_{0.07}\right) \mathrm{Co}_{0.50}$ and $\left(\mathrm{Ti}_{0.24} \mathrm{Nb}_{0.11}\right) \mathrm{Co}_{0.65}$ in accordance with the two intermetallics detected via XRD. It is interesting to note that, in the SEM image, two different contrasts in the binder were observed only in this cermet (figure $3 b$ ), which could correspond to these two intermetallic compounds.

Regarding the ceramic carbonitride phases, XEDS-SEM analyses allowed the discrimination between the core and rim chemical compositions in cermets TiNb20Co, TiTa20Co, TiTa10Co and TiTa20CO5Mo, as shown in table 2. In all of these compounds, the composition of the core phase was in good agreement with the intended stoichiometry, and the rim phase always exhibited a higher Ti content compared to the core phase. This result is in concordance with the inverse core-rim microstructure observed in figure 2, and is common in this type of cermet based on solid solution carbonitrides [30]. A Ti-rich rim phase is also in agreement with intermetallic phases that are richer in $\mathrm{Nb}$ or $\mathrm{Ta}$ (table 2) than the starting nominal composition (table 1).

\subsection{Mechanical properties.}

The Vickers microhardness and fracture toughness of the cermets are shown in table 4. High microhardness values were found, between $13.8 \mathrm{GPa}$ and $15.7 \mathrm{GPa}$, except for the TiTa10Co cermet $(9.6 \mathrm{GPa})$ due to its higher porosity. These values are comparable to those found in cermets with a similar composition sintered by SPS [29] and $\sim 3 \mathrm{GPa}$ higher than those sintered using the PS method [31]. For example, cermets 
similar to Ti20Co and TiTa20Co presented Vickers microhardness values of $11.7 \mathrm{GPa}$ and 11.9 GPa, respectively, with PS sintering, while values of $14.4 \mathrm{GPa}$ and $15.7 \mathrm{GPa}$, were observed with HP (table 4). This improvement can be attributed to the reduction of both porosity, which was practically nonexistent (table 3), and ceramic particle size (Hall-Petch strengthening) $[\mathrm{d}=4.38 \mu \mathrm{m}$ (PS) vs. $2.32 \mu \mathrm{m}$ (HP) for the cermet Ti20Co and $\mathrm{d}=2.73 \mu \mathrm{m}$ (PS) vs. $1.18 \mu \mathrm{m}$ (HP) for the cermet TiTa20Co). Moreover, as the average ceramic particle size is reduced, the binder mean free path $(\lambda)$ is also reduced (if the binder content is maintained) [48], with a consequent influence on the constriction and strengthening of the binder phase.

The fracture toughness of the cermets was always below $5 \mathrm{MPam}^{1 / 2}$. This low toughness was the consequence of the formation of the intermetallic compounds that greatly reduce the ductility of the binder phase, which is detrimental for the mechanical properties of cermets $[14,31]$. The fracture toughness was even lower in those cermets containing $\mathrm{Ta}$ and $\mathrm{Nb}$. The presence of these elements in the structure of the host Co-Ti intermetallic phases is expected to even increase the brittleness due to the higher bulk modulus of $\mathrm{Ta}$ and $\mathrm{Nb}$ compared with $\mathrm{Ti}[\mathrm{K}(\mathrm{Ti})=110 \mathrm{GPa} ; \mathrm{K}(\mathrm{Nb})=170 \mathrm{GPa} ; \mathrm{K}(\mathrm{Ta})=$ $200 \mathrm{GPa}$ [ [49]. Low fracture toughness values have always been obtained in cermets, regardless of the sintering method used, if intermetallic phases are present in the binder phase [29].

The Young's modulus and Poisson's ratio of the cermets determined using the resonance frequency method are also shown in table 4 . The Poisson's ratio values were in a narrow range for all the cermets $(0.179-0.192)$, similar to those of pure ceramic materials (TiC: $0.17-0.19$ [45]) and lower than the typical values of commercial cermets 
(0.21-0.22) [50]. The presence of the intermetallic compounds, which possess a covalent component in the bonding between Co and the transition metal atoms [51], should lead to a reduction in the Poisson's ratio. Note that, generally, this parameter for covalent and metallic bonds is approximately 0.1 and 0.33 , respectively [52].

Similar Young's modulus values (between $311 \mathrm{GPa}$ and $348 \mathrm{GPa}$ ) were also observed in cermets with the same binder content (table 4). The small differences were attributed to the different phases and chemical compositions observed for both the ceramic and binder components in these cermets (table 2). The TiTa10Co cermet, with a lower binder content (10 wt \% of Co), possessed an appreciably lower value of $247 \mathrm{GPa}$, which was again associated with the detrimental effect of the high porosity (5.9 vol\%).

A linear correlation between hardness and Young's modulus was observed (figure 5), with the general trend of the higher the elastic modulus, the higher the hardness. Young's modulus is an intrinsic material property related primarily to atomic bonding. However, hardness is a more complex property involving elasticity and plasticity and is governed by both intrinsic and extrinsic properties, i.e., defects, stress fields and morphology. In hard materials, in which the contribution of elastic and plastic deformations to the total deformation are similar, it is generally found that hardness is directly dependent on the elastic modulus [53].

The flexural strength or modulus of rupture, determined by four-point flexural tests and extrapolated to a zero level of porosity using the Knudsen equation, is shown in table 4. The low values obtained, closer to the values observed in ceramics, corroborate the detrimental effect of the presence of intermetallic compounds acting as binders. Moreover, the introduction of $\mathrm{Nb}$ or Ta into cermets significantly decreased the strength, 
although an increase in this property was expected according to the decreased size of the ceramic particles observed when these elements were added (table 3). Therefore, it is clear that the greater embrittlement of the intermetallic compounds with $\mathrm{Ta}, \mathrm{Nb}$ and $\mathrm{Mo}$ in their structures $[14,31]$ caused a greater detrimental effect on the flexural strength.

Nanoindentation measurements were used to determine and differentiate the mechanical properties of the ceramic and binder phases in the cermets. Representative nanoindentations are shown in figures 6 and 7, in which the different indentation sizes for the ceramic and intermetallic phases are clearly observable and are indicative of different mechanical properties. Moreover, the characteristic load-displacement curves of the nanoindentations for cermets Ti20Co, TiNb20Co, TiTa20Co, TiTa10Co and TiTa20Co5Mo are presented in figure 8, wherein the dissimilar penetration depths between the ceramic and metallic binder phases are visible, as a consequence of the different mechanical behaviors of these phases. Table 5 shows the nanohardness and nano-Young's modulus of both components. The ceramic component showed nanohardness values ranging from $\sim 26 \mathrm{GPa}$ to $\sim 29 \mathrm{GPa}$, whereas the binder phase had values from $\sim 14 \mathrm{GPa}$ to $16 \mathrm{GPa}$. The hardness for the carbonitride phases was consistent with the values reported for the following binary ceramic phases: TiC, TiN, $\mathrm{NbC}, \mathrm{NbN}, \mathrm{TaC}$ and $\mathrm{TaN}$ [45]. However, the nanohardness obtained for the binder phases composed of intermetallic compounds was, as expected, significantly higher than the values found for constrained Co in hardmetals and cermets $[14,54,55]$. The values observed were more characteristic of brittle intermetallic compounds. The nano-Young's modulus determined for the ceramic phase, between $\sim 340 \mathrm{GPa}$ and $\sim 400 \mathrm{GPa}$, was also close to those reported for the binary ceramic phases [45]. Moreover, the values for the 
binder, between $\sim 240 \mathrm{GPa}$ and $\sim 320 \mathrm{GPa}$, were also substantially higher that those corresponding to Co (209 GPa) or $\alpha$-Co alloy [14] due again to the presence of the intermetallic compounds.

\section{Conclusions}

The effect of HP sintering conditions on the chemical, microstructural and mechanical properties of $(\mathrm{Ti}, \mathrm{Mt1})(\mathrm{C}, \mathrm{N})$-Co materials $(\mathrm{Mt} 1=\mathrm{No}$ element, $\mathrm{Nb}, \mathrm{Ta}$ and/or Mo) were investigated, and the major conclusions are summarized as follows:

1. Cermets based on titanium carbonitride developed using the MSR method were successfully densified by induction HP with a much shorter time and lower temperature than PS methods, using experimental conditions (sintering temperature, dwell time and applied pressure) close to those generally used by the most expensive SPS technology.

2. For the developed cermets, the ceramic phase consisted of a complex solid solution carbonitride (excepting the Ti20Co cermet, containing only Ti), and the binder phase was formed by Ti-Mt-Co intermetallic compounds (Mt=No element, $\mathrm{Nb}$, Ta and/or Mo).

3. When $\mathrm{Ta}, \mathrm{Nb}$ and $\mathrm{Mo}$ (this last as carbide) were added to the initial mixture, smaller ceramic grains were observed, which suggests that ceramic growth was hindered by the presence of these elements in the host titanium carbonitride structure.

4. Although cermets sintered by HP had higher hardness values than those sintered by PS methods due to a lower porosity and ceramic particle size, the formation of intermetallic compounds acting as binders resulted in low toughness and fracture strength values in the cermets. The presence of $\mathrm{Ta}, \mathrm{Nb}$ or Mo in the structure of the host Ti-Co intermetallic 
compounds increased binder brittleness, reducing even more the strength of the cermets containing these transition metals.

5. The nanohardness and nano-Young's modulus values obtained for the ceramic component were in agreement with the values reported for the binary ceramic phases, whereas the corresponding values for the binder phase were significantly higher than the values for constrained Co in hardmetals and cermets and were characteristic of brittle intermetallic phases. 


\section{Acknowledgments}

This work was supported by the Spanish government under grant No. MAT201122981, which is financed in part by the European Regional Development Fund of 2007-

2013. Ernesto Chicardi was supported under a 2015 postdoctoral grant, which is financed by the FONDECYT fund (Government of Chile).

Finally, the authors would like to thank to Mr. Daniele Dalle Fabbriche and Mr. Cesare Melandri (Istituto di Scienza e Tecnologia dei Materiali Ceramici, ISTECFaenza) for their assistance with hot-pressing and mechanical testing, respectively. 


\section{References}

[1] A. Rajabi, M.J. Ghazali, J. Syarif, A.R. Daud, Development and application of tool wear: A review of the characterization of TiC-based cermets with different binders, Chemical Engineering Journal 255 (2014) 445-452.

[2] E. Chicardi, F.J. Gotor, J.M. Cordoba, Enhanced oxidation resistance of Ti(C,N)based cermets containing Ta, Corrosion Science 84 (2014) 11-20.

[3] E. Chicardi, J.M. Córdoba, F.J. Gotor, High temperature oxidation resistance of (Ti,Ta)(C,N)-based cermets, Corrosion Science 102 (2016) 125-136.

[4] P. Ettmayer, H. Kolaska, W. Lengauer, K. Dreyer, Ti(C,N) cermets-Metallurgy and properties, International Journal of Refractory Metals \& Hard Materials (1994) 343-351.

[5] S. Chao, N. Liu, Y. Yuan, C. Han, Y. Xu, M. Shi, J. Feng, Microstructure and mechanical properties of ultrafine Ti(CN)-based cermets fabricated from nano/submicron starting powders, Ceramics International 31 (2005) 851-862.

[6] M. Bannister, M.F. Ashby, The deformation and fracture of constrained metal sheets, Acta Metallurgica Et Materialia 39 (1991) 2575-2582.

[7] A. Borrell, M. Dolores Salvador, V. Garcia-Rocha, A. Fernandez, E. Chicardi, F.J. Gotor, Spark plasma sintering of TiyNb1-yCxN1-x monolithic ceramics obtained by mechanically induced self-sustaining reaction, Materials Science and Engineering aStructural Materials Properties Microstructure and Processing 543 (2012) 173-179.

[8] M. Jalaly, M.S. Bafghi, M. Tamizifar, F.J. Gotor, Mechanosynthesis of nanocrystalline ZrB2-based powders by mechanically induced self-sustaining reaction method, Advances in Applied Ceramics 112 (2013) 383-388.

[9] M.A. Roldan, M.D. Alcala, C. Real, Mechanically induced self-propagating reaction of vanadium carbonitride, Ceramics International 41 (2015) 4688-4695.

[10] M.J. Sayagues, Aviles, M.A, Córdoba J.M., Gotor F.J., Self-propagating combustion synthesis by MSR: An efficient and simple method to produce (Ti, Zr, Hf)B2-Al2O3 powder nanocomposites, Powder Technol. 256 (2014) 244-250.

[11] T.D. Huy, H. Fujiwara, R. Yoshida, D.T. Binh, H. Miyamoto, Microstructure and Mechanical Properties of TiAl3/Al2O3 in situ Composite by Combustion Process, Materials Transactions 55 (2014) 1091-1093.

[12] M.A. Aviles, E. Chicardi, J.M. Cordoba, M.J. Sayagues, F.J. Gotor, In Situ Synthesis of Ceramic Composite Materials in the Ti-B-C-N System by a Mechanically Induced Self-Sustaining Reaction, Journal of the American Ceramic Society 95 (2012) 2133-2139.

[13] E. Chicardi, J.M. Córdoba, M.J. Sayagués, F.J. Gotor, Absence of the core-rim microstructure in TixTa1-XCyN1-y-based cermets developed from a pre-sintered carbonitride master alloy, International Journal of Refractory Metals and Hard Materials 33 (2012) 38-43.

[14] E. Chicardi, Y. Torres, M.J. Sayagues, V. Medri, C. Melandri, J.M. Cordoba, F.J. Gotor, Toughening of complete solid solution cermets by graphite addition, Chemical Engineering Journal 267 (2015) 297-305.

[15] J.M. Cordoba, E. Chicardi, F.J. Gotor, Liquid-phase sintering of Ti(C,N)-based cermets. The effects of binder nature and content on the solubility and wettability of hard ceramic phases, Journal of Alloys and Compounds 559 (2013) 34-38. 
[16] J.M. Cordoba, E. Chicardi, M.A. Aviles, F.J. Gotor, Formation of the complete range of Ti5Si3-xGex solid solutions via mechanically induced self-sustained reactions, Intermetallics 19 (2011) 1688-1692.

[17] S. Murali, T. Sritharan, P. Hing, Combustion synthesis of a alpha ' AlFeSi intermetallic, Int. J. Powder Metall. 37 (2001) 67-74.

[18] S. Doppiu, M. Monagheddu, G. Cocco, F. Maglia, U. Anselmi-Tamburini, Z.A. Munir, Mechanochemistry of the titanium-silicon system: Compositional effects, J. Mater. Res. 16 (2001) 1266-1279.

[19] B. Zou, J. Xu, Y. Wang, S. Zhao, X. Fan, Y. Hui, X. Zhou, W. Huang, X. Cai, S. Tao, H. Ma, X. Cao, Self-propagating high-temperature synthesis of TiC-TiB2-based Co cermets from a Co-Ti-B4C system and fabrication of coatings using the cermet powders, Chemical Engineering Journal 233 (2013) 138-148.

[20] Y.X. Li, J.D. Hu, H.Y. Wang, Z.X. Guo, Study of TiC/Ni3Al composites by laser ignited self-propagating high-temperature synthesis (LISHS), Chemical Engineering Journal 140 (2008) 621-625.

[21] F.J. Gotor, M. Achimovicova, C. Real, P. Balaz, Influence of the milling parameters on the mechanical work intensity in planetary mills, Powder Technol. 233 (2013) 1-7.

[22] J.M. Cordoba, E. Chicardi, F.J. Gotor, Development of multicomponent-multiphase materials based on $(\mathrm{Ti}, \mathrm{Ta}, \mathrm{Nb}) \mathrm{CxN} 1-\mathrm{x}$ carbonitride solid solutions, Chemical Engineering Journal 192 (2012) 58-66.

[23] E. Chicardi, Y. Torres, J.M. Córdoba, M.J. Sayagués, J.A. Rodríguez, F.J. Gotor, Effect of sintering time on the microstructure and mechanical properties of $(\mathrm{Ti}, \mathrm{Ta})(\mathrm{C}, \mathrm{N})$ based cermets, International Journal of Refractory Metals and Hard Materials (2013).

[24] A. Yabuki, K. Okumura, I.W. Fathona, Transparent conductive coatings of hotpressed ITO nanoparticles on a plastic substrate, Chemical Engineering Journal 252 (2014) 275-280.

[25] K.V. Manukyan, S.V. Aydinyan, K.G. Kirakosyan, S.L. Kharatyan, G. Blugan, U. Müller, J. Kuebler, Molten salt-assisted combustion synthesis and characterization of MoSi2 and MoSi2-Si3N4 composite powders, Chemical Engineering Journal 143 (2008) 331-336.

[26] F. Monteverde, V. Medri, A. Bellosi, Microstructure of hot-pressed Ti(C,N)-based cermets, Journal of the European Ceramic Society 22 (2002) 2587-2593.

[27] J.F. Sun, F.M. Zhang, J. Shen, Characterizations of ball-milled nanocrystalline WCCo composite powders and subsequently rapid hot pressing sintered cermets, Materials Letters 57 (2003) 3140-3148.

[28] J.M. Torralba, M. Campos, Toward high performance in Powder Metallurgy, Revista De Metalurgia 50 (2014).

[29] J.M. Cordoba, E. Chicardi, R. Poyato, F.J. Gotor, V. Medri, S. Guicciardi, C. Melandri, Spark plasma sintering of TixTa1-xC0.5N0.5-based cermets: Effects of processing conditions on chemistry, microstructure and mechanical properties, Chemical Engineering Journal 230 (2013) 558-566.

[30] E. Chicardi, J.M. Córdoba, M.J. Sayagués, F.J. Gotor, Inverse core-rim microstructure in $(\mathrm{Ti}, \mathrm{Ta})(\mathrm{C}, \mathrm{N})$-based cermets developed by a mechanically induced selfsustaining reaction, International Journal of Refractory Metals and Hard Materials 31 (2012) 39-46. 
[31] E. Chicardi, Y. Torres, J.M. Cordoba, P. Hvizdos, F.J. Gotor, Effect of tantalum content on the microstructure and mechanical behavior of cermets based on (TixTa1$\mathrm{x})(\mathrm{C} 0.5 \mathrm{~N} 0.5)$ solid solutions, Materials \& Design 53 (2014) 435-444.

[32] A. Thorvaldsen, The intercept method .2. Determination of spatial grain size, Acta Materialia 45 (1997) 595-600.

[33] K. Niihara, A fracture-mechanics analysis of indentation-induced Palmqvist crack in ceramics, Journal of Materials Science Letters 2 (1983) 221-223.

[34] R. Spiegler, S. Schmauder, L. Sigl, Evaluation of WC-Co Alloys by Indentation Testing, Journal of Hard Materials 1 (1990) 147-158.

[35] R. Warren, H. Matzke, Indentation Testing of a Broad Range of Cemented Carbides, in: R.K. Viswanadham, D.J. Rowcliffe, J. Gurland (Eds.) Science of Hard Materials, Springer US1983, pp. 563-582.

[36] D.W. Haines, J.M. Leban, C. Herbe, Determination of Young's modulus for spruce, fir and isotropic materials by the resonance flexure method with comparisons to static flexure and other dynamic methods, Wood Science and Technology 30 (1996) 253-263.

[37] W.C. Oliver, G.M. Pharr, An improved technique for determining hardness and elastic-modulus using load and displacement sensing indentation experiments, Journal of Materials Research 7 (1992) 1564-1583.

[38] J.M. Córdoba, M.J. Sayagués, M.D. Alcalá, F.J. Gotor, Monophasic TiyNb1 YCxN1 - x nanopowders obtained at room temperature by MSR, Journal of Materials Chemistry 17 (2007) 650-653.

[39] K.V. Manukyan, Y.-C. Lin, S. Rouvimov, P.J. McGinn, A.S. Mukasyan, Microstructure-reactivity relationship of Ti plus $\mathrm{C}$ reactive nanomaterials, Journal of Applied Physics 113 (2013).

[40] J.M. Córdoba, M.J. Sayagués, M.D. Alcalá, F.J. Gotor, Synthesis of titanium carbonitride phases by reactive milling of the elemental mixed powders, Journal of the American Ceramic Society 88 (2005) 1760-1764.

[41] O.H. Baker H, Alloy Phase Diagrams, ASM Handbook1992.

[42] M. Jiang, G. Saren, S.-y. Yang, H.-x. Li, S.-m. Hao, Phase equilibria in Co-rich region of Co-Ti-Ta system, Transactions of Nonferrous Metals Society of China 21 (2011) 2391-2395.

[43] H. Baker, H. Okamoto, ASM Handbook, Volume 03 - Alloy Phase Diagrams, ASM International.

[44] G. Madras, B.J. McCoy, Distribution kinetics of Ostwald ripening at large volume fraction and with coalescence, Journal of Colloid and Interface Science 261 (2003) 423433.

[45] W. Lengauer, Transition Metal Carbides, Nitrides, and Carbonitrides, Handbook of Ceramic Hard Materials, Wiley-VCH Verlag GmbH2008, pp. 202-252.

[46] Y. Li, N. Liu, X. Zhang, C. Rong, Effect of Mo addition on the microstructure and mechanical properties of ultra-fine grade TiC-TiN-WC-Mo2C-Co cermets, International Journal of Refractory Metals and Hard Materials 26 (2008) 190-196.

[47] H. Matsubara, S.G. Shin, T. Sakuma, Growth of carbide particle in TiC-Ni and TiCMo2C-Ni cermets during liquid-phase sintering, Mater. Trans. JIM 32 (1991) 951-956.

[48] B. Roebuck, E.G. Bennett, Phase size distribution in WC/Co hardmetal, Metallography 19 (1986) 27-47. 
[49] J. Kaye, T. Laby, Tables of physical and chemical constants, 15th edition ed., Longman, London, UK, 1993.

[50] H. Kolaska, F. Pulvermetallurgie, Pulvermetallurgie der Hartmetalle, Fachverband Pulvermetallurgie1992.

[51] G.A. Botton, C.J. Humphreys, Determining the bonding in intermetallics using electron energy loss spectroscopy and density functional theory, Intermetallics 7 (1999) 829-833.

[52] J. Haines, J.M. Leger, G. Bocquillon, Synthesis and design of superhard materials, Annual Review of Materials Research 31 (2001) 1-23.

[53] Y.T. Cheng, C.M. Cheng, Scaling, dimensional analysis, and indentation measurements, Materials Science and Engineering: R: Reports 44 (2004) 91-149.

[54] A. Duszova, R. Halgas, M. Bl'anda, P. Hvizdos, F. Lofaj, J. Dusza, J. Morgiel, Nanoindentation of WC-Co hardmetals, Journal of the European Ceramic Society 33 (2013) 2227-2232.

[55] V. Bonache, E. Rayon, M.D. Salvador, D. Busquets, Nanoindentation study of WC12 Co hardmetals obtained from nanocrystalline powders: Evaluation of hardness and modulus on individual phases, Materials Science and Engineering a-Structural Materials Properties Microstructure and Processing 527 (2010) 2935-2941. 


\section{Figure Captions}

Figure 1. XRD patterns of a) powdered cermets after MSR synthesis and b) sintered cermets after HP. $(\bullet)(\mathrm{Ti}, \mathrm{Mt})(\mathrm{C}, \mathrm{N})$ with space group symmetry $[\mathrm{Fm}-3 \mathrm{~m}] ;(\bullet)$ Co-based alloy $[\mathrm{Pm} 3 \mathrm{~m}] ;(*)$ cubic $(\mathrm{Ti}, \mathrm{Mt}) \mathrm{Co}[\mathrm{Pm} 3 \mathrm{~m}] ;(\mathrm{O})$ Cubic $(\mathrm{Ti}, \mathrm{Mt}) \mathrm{Co}_{2}[\mathrm{Fd} 3 \mathrm{~m}] ;(\mathrm{Mt}=\mathrm{No}$ element, Ta or $\mathrm{Nb}) ;(\Delta)$ Hexagonal (Ti, Ta, Mo)Co2 [P63/mmc].

Figure 2. Characteristic SEM images of sintered cermets at low magnification: a) Ti20Co; b) TiNb20Co; c) TiTa20Co; d) TiTa10Co; e) TiTa20Co5Mo. Occluded binder is marked by arrows, and ceramic particles with a core-rim microstructure are marked by squares.

Figure 3. Characteristic SEM images for sintered cermets at high magnification: a) Ti20Co; b) TiNb20Co; c) TiTa20Co; d) TiTa10Co; e) TiTa20Co5Mo. Occluded binder is marked by arrows, and ceramic particles with a core-rim microstructure are indicated with squares. Additionally, the core, rim and binder phases with stoichiometries of $1: 1$ and $1: 2$ are labeled as $c, r, b 1$ and $b 2$, respectively, with their corresponding compositions shown in table 2.

Figure 4. Ceramic particle size distribution for sintered cermets.

Figure 5. Microhardness vs. Young's modulus for the sintered cermets: a) Ti20Co; b) TiNb20Co; c) TiTa20Co; d) TiTa10Co; e) TiTa20Co5Mo. 
Figure 6. SEM images showing characteristic nanoindentations for the ceramic (C) and binder phases (B) in cermets Ti20Co, TiNb20Co and TiTa20Co. The indentation boundaries are indicated with white line triangles.

Figure 7. SEM images showing characteristic nanoindentations for the ceramic (C) and binder phases (B) in cermets TiTa10Co and TiTa20CO5Mo. The indentation boundaries are indicated with white line triangles.

Figure 8. Characteristic load-displacement curves of nanoindentations for cermets Ti20Co, TiNb20Co, TiTa20Co, TiTa10Co and TiTa20Co5Mo. Continuous lines = Binder phases; Dotted lines $=$ Ceramic phases. 
Table 1. Nominal composition of cermets synthesized under MSR and HP sintering conditions.

\begin{tabular}{|c|c|c|c|c|c|}
\hline \multirow{2}{*}{ Cermet label } & \multicolumn{2}{|c|}{ Phase composition } & \multicolumn{3}{|c|}{ Sintering conditions } \\
\hline & Ceramic & Binder & $\mathrm{T}\left({ }^{\circ} \mathrm{C}\right)$ & $t(\min )$ & $\mathbf{P}(\mathbf{M P a})$ \\
\hline Ti20Co & $\mathrm{TiC}_{0.5} \mathrm{~N}_{0.5}$ & \multirow{3}{*}{$20 \mathrm{wt} \% \mathrm{Co}$} & 1300 & 8 & \multirow{5}{*}{20} \\
\hline TiNb20Co & $\mathrm{Ti}_{0.9} \mathrm{Nb}_{0.1} \mathrm{C}_{0.5} \mathrm{~N}_{0.5}$ & & 1320 & 3 & \\
\hline TiTa20Co & $\mathrm{Ti}_{0.9} \mathrm{Ta}_{0.1} \mathrm{C}_{0.5} \mathrm{~N}_{0.5}$ & & 1360 & 3 & \\
\hline TiTa10Co & $\mathrm{Ti}_{0.9} \mathrm{Ta}_{0.1} \mathrm{C}_{0.5} \mathrm{~N}_{0.5}$ & $10 \mathrm{wt} \% \mathrm{Co}$ & 1360 & 5 & \\
\hline TiTa20Co5Mo & $\begin{array}{c}\mathrm{Ti}_{0.9} \mathrm{Ta}_{0.1} \mathrm{C}_{0.5} \mathrm{~N}_{0.5} \\
+ \\
5 \mathrm{wt} \% \mathrm{Mo}_{2} \mathrm{C}\end{array}$ & $20 \mathrm{wt} \% \mathrm{Co}$ & 1360 & 5 & \\
\hline
\end{tabular}


Table 2. Lattice parameters of the carbonitride phases before (a1) and after (a2) the sintering process and transition metal compositions (at.\%) of the ceramic and binder phases after sintering.

\begin{tabular}{|c|c|c|c|c|c|c|}
\hline & & & \multicolumn{4}{|c|}{ XEDS-SEM (at.\%) } \\
\hline Cermet & a1 (̊) & a2 (̊̊) & Core & Rim & $\begin{array}{c}\text { Binder } \\
(1: 1)\end{array}$ & $\begin{array}{c}\text { Binder } \\
(1: 2)\end{array}$ \\
\hline Ti20Co & $4.300(8)$ & $4.302(2)$ & Ti: 100 & - & $\begin{array}{r}\text { Ti: } 48.8 \\
\text { Co: } 51.2\end{array}$ & - \\
\hline TiNb20Co & $4.321(9)$ & $4.320(2)$ & $\begin{array}{l}\mathrm{Ti}: 90.8 \\
\mathrm{Nb}: 9.2\end{array}$ & $\begin{array}{l}\mathrm{Ti}: 91.9 \\
\mathrm{Nb}: 8.1\end{array}$ & $\begin{array}{c}\mathrm{Ti}: 43.1 \\
\mathrm{Nb}: 6.5 \\
\mathrm{Co}: 50.4\end{array}$ & $\begin{array}{c}\text { Ti: } 24.1 \\
\text { Nb: } 11.0 \\
\text { Co: } 64.9\end{array}$ \\
\hline TiTa20Co & $4.312(6)$ & $4.311(1)$ & $\begin{array}{l}\text { Ti: } 89.9 \\
\text { Ta: } 10.1\end{array}$ & $\begin{array}{l}\text { Ti: } 91.9 \\
\text { Ta: } 8.1\end{array}$ & - & $\begin{array}{c}\text { Ti: } 31.8 \\
\text { Ta: } 4.4 \\
\text { Co: } 63.8\end{array}$ \\
\hline TiTa10Co & $4.315(5)$ & $4.311(1)$ & $\begin{array}{l}\text { Ti: } 90.1 \\
\text { Ta: } 9.9\end{array}$ & $\begin{array}{l}\text { Ti: } 94.1 \\
\text { Ta: } 5.9\end{array}$ & $\begin{array}{c}\text { Ti: } 45.0 \\
\text { Ta: } 4.3 \\
\text { Co: } 50.7\end{array}$ & - \\
\hline TiTa20Co5Mo & $4.321(2)$ & $4.323(2)$ & $\begin{array}{c}\text { Ti: } 88.4 \\
\text { Ta: } 11.6\end{array}$ & $\begin{array}{l}\text { Ti: } 92.7 \\
\text { Ta: } 7.3\end{array}$ & - & $\begin{array}{c}\text { Ti: } 26.4 \\
\text { Ta: } 6.2 \\
\text { Mo: } 4.0 \\
\text { Co: } 63.6\end{array}$ \\
\hline
\end{tabular}


Table 3. Mean carbonitride particle size (d), binder volumetric percentage (BF) and porosity volumetric percentage (e) determined by image analysis of SEM micrographs and BF estimated according to the rule of mixture from the nominal compositions in table 1.

\begin{tabular}{|c|c|c|c|c|}
\cline { 2 - 5 } \multicolumn{1}{c|}{} & \multicolumn{3}{c|}{ Image Analysis } & Rule of mixtures \\
\hline Cermet & d $(\boldsymbol{\mu m})$ & BF (\% vol.) & e (\% vol.) & BF (\% vol.) \\
\hline Ti20Co & 2.32 & 31.6 & $\sim 0$ & 14.5 \\
\hline TiNb20Co & 1.80 & 33.4 & $\sim 0$ & 15.4 \\
\hline TiTa20Co & 1.18 & 34.0 & $\sim 0$ & 17.5 \\
\hline TiTa10Co & 0.96 & 20.6 & $\sim 5.9$ & 7.8 \\
\hline TiTa20Co5Mo & 0.77 & 32.3 & $\sim 0$ & 14.4 \\
\hline
\end{tabular}


Table 4. Vickers microhardness $\left(\mathrm{H}_{\mathrm{v}}\right)$, fracture toughness $\left(\mathrm{K}_{\mathrm{IC}}\right)$, Poisson's ratio $(v)$, Young's modulus (E) and flexural strength $(\sigma)$ of the sintered cermets.

\begin{tabular}{|c|c|c|c|c|c|}
\hline Cermet & $\begin{array}{c}\text { Hv } \\
(\mathbf{G P a})\end{array}$ & $\begin{array}{c}\mathbf{K I C}_{\mathbf{I C}} \\
\left(\mathbf{M P a} \cdot \mathbf{m}^{\mathbf{1} / \mathbf{2}}\right)\end{array}$ & $\mathbf{v}$ & $\begin{array}{c}\mathbf{E} \\
(\mathbf{G P a})\end{array}$ & $\begin{array}{c}\boldsymbol{\sigma} \\
(\mathbf{M P a})\end{array}$ \\
\hline Ti20Co & $14.4 \pm 0.3$ & $4.6 \pm 0.32$ & $0.191 \pm 0.003$ & $306 \pm 14$ & $485 \pm 47$ \\
\hline TiNb20Co & $13.8 \pm 0.2$ & $3.6 \pm 0.16$ & $0.186 \pm 0.004$ & $299 \pm 13$ & $253 \pm 22$ \\
\hline TiTa20Co & $15.7 \pm 0.8$ & $3.1 \pm 0.28$ & $0.188 \pm 0.007$ & $332 \pm 12$ & $281 \pm 19$ \\
\hline TiTa10Co & $9.6 \pm 0.9$ & $3.8 \pm 0.20$ & $0.179 \pm 0.011$ & $247 \pm 10$ & $270 \pm 15$ \\
\hline TiTa20Co5Mo & $15.8 \pm 0.6$ & $3.8 \pm 0.15$ & $0.194 \pm 0.009$ & $320 \pm 5$ & $230 \pm 9$ \\
\hline
\end{tabular}


Table 5. Nanohardness and nano-Young's modulus values for the ceramic and binder phases of the sintered cermets.

\begin{tabular}{|c|c|c|c|c|}
\hline \multirow{2}{*}{ Cermet } & \multicolumn{2}{|c|}{ Ceramic } & \multicolumn{2}{c|}{ Binder } \\
\cline { 2 - 5 } & $\mathbf{H}_{\mathbf{v}}(\mathbf{G P a})$ & $\mathbf{E}(\mathbf{G P a})$ & $\mathbf{H}_{\mathbf{v}}(\mathbf{G P a})$ & $\mathbf{E}(\mathbf{G P a})$ \\
\hline Ti20Co & $28.8 \pm 2.3$ & $408 \pm 40$ & $13.7 \pm 1.3$ & $289 \pm 37$ \\
\hline TiNb20Co & $28.5 \pm 2.9$ & $400 \pm 35$ & $15.4 \pm 2.6$ & $303 \pm 22$ \\
\hline TiTa20Co & $26.7 \pm 1.9$ & $378 \pm 21$ & $14.1 \pm 2.0$ & $241 \pm 26$ \\
\hline TiTa10Co & $26.6 \pm 4.0$ & $337 \pm 35$ & $14.9 \pm 3.1$ & $277 \pm 25$ \\
\hline TiTa20Co5Mo & $28.5 \pm 3.8$ & $387 \pm 29$ & $14.0 \pm 2.3$ & $317 \pm 26$ \\
\hline
\end{tabular}



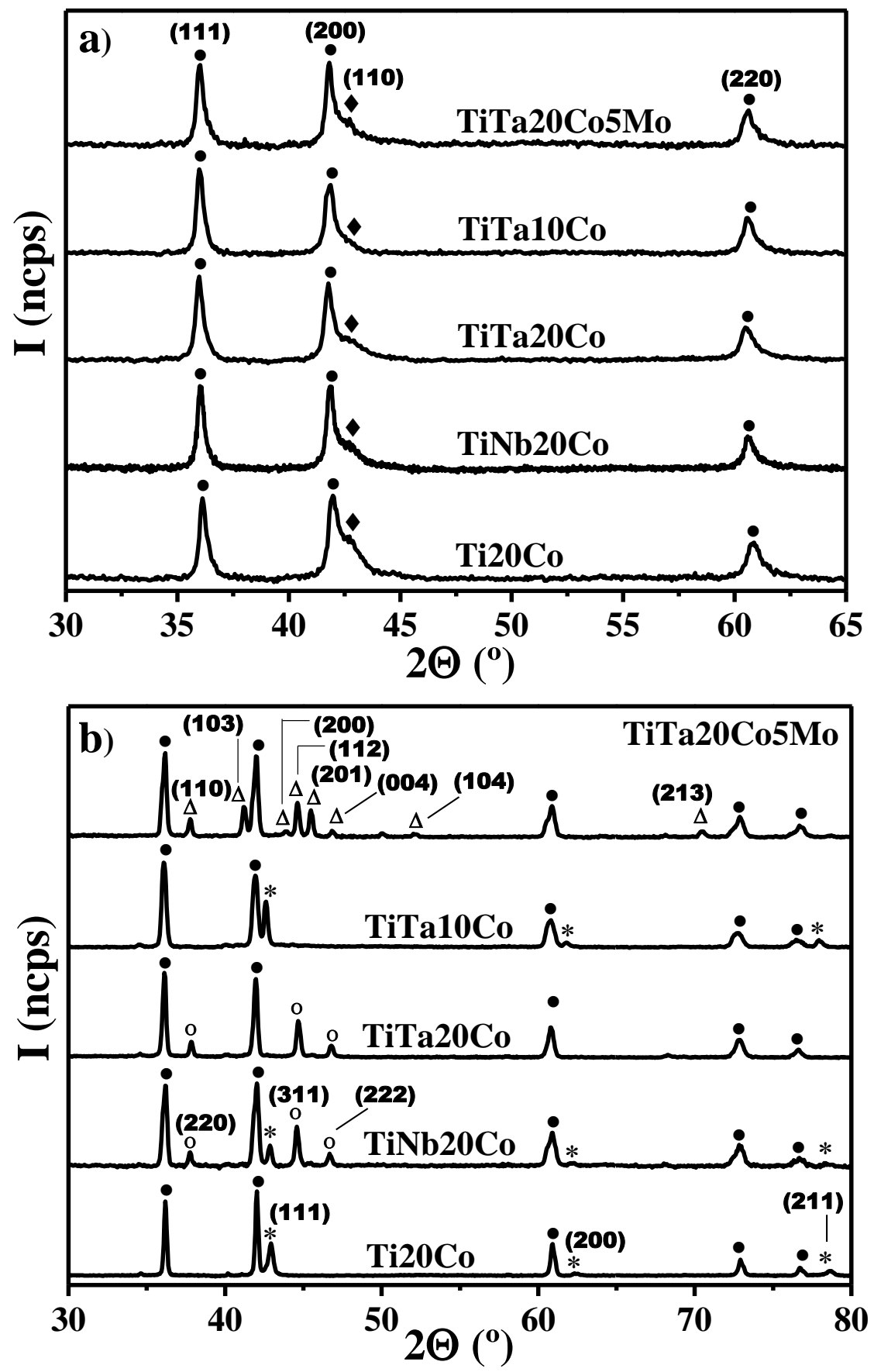

Figure 1 

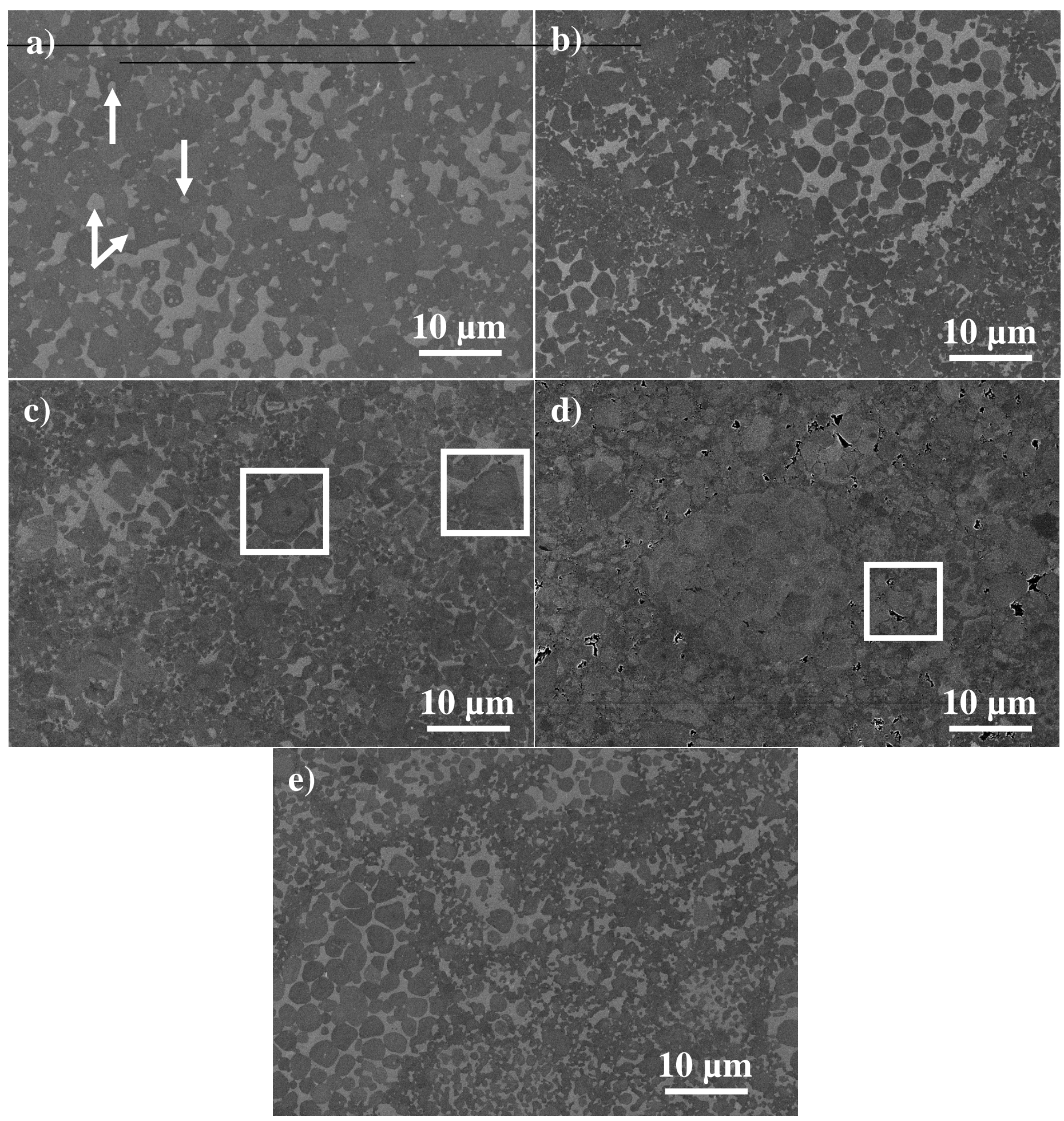

Figure 2 

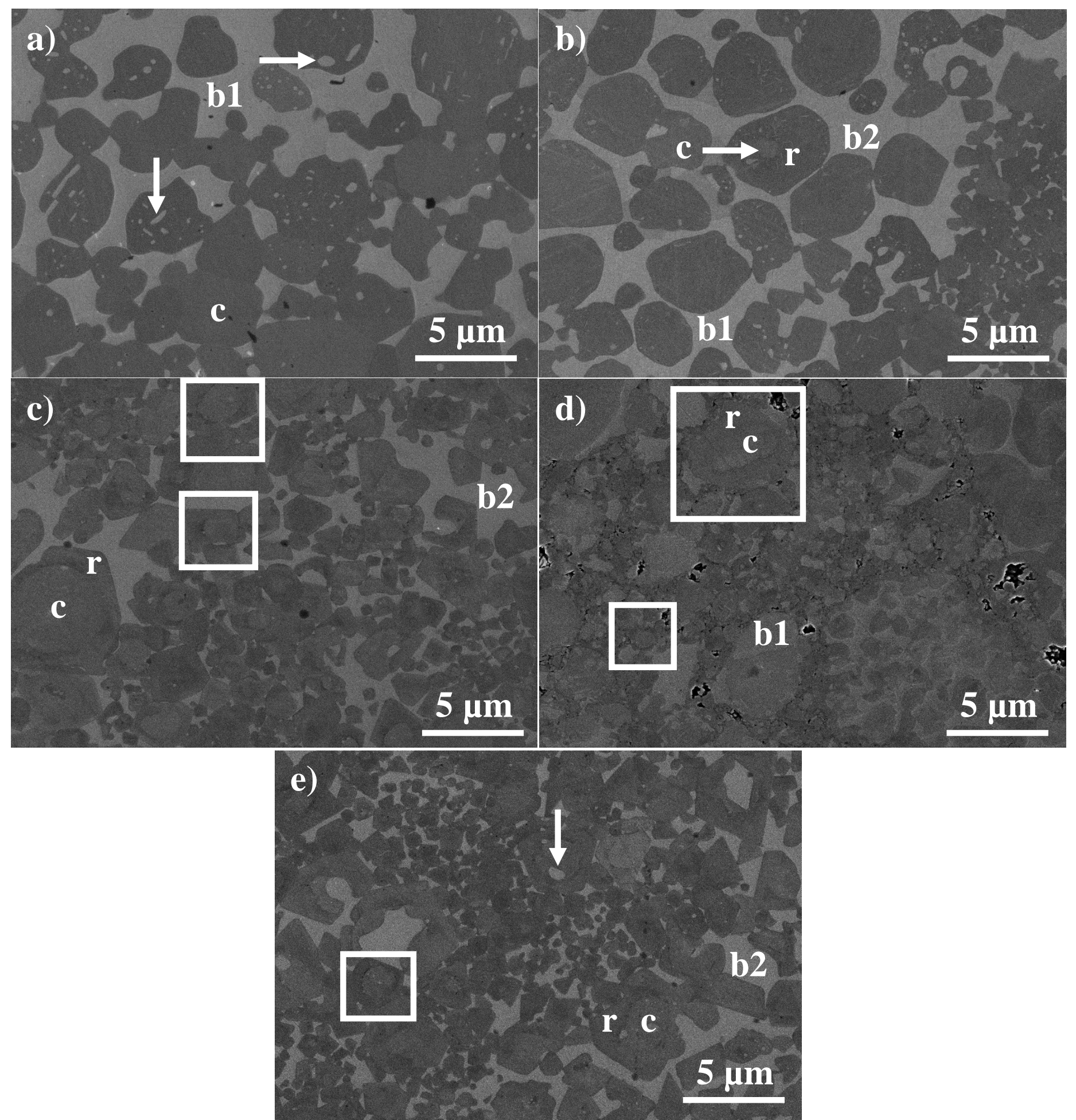

Figure 3 

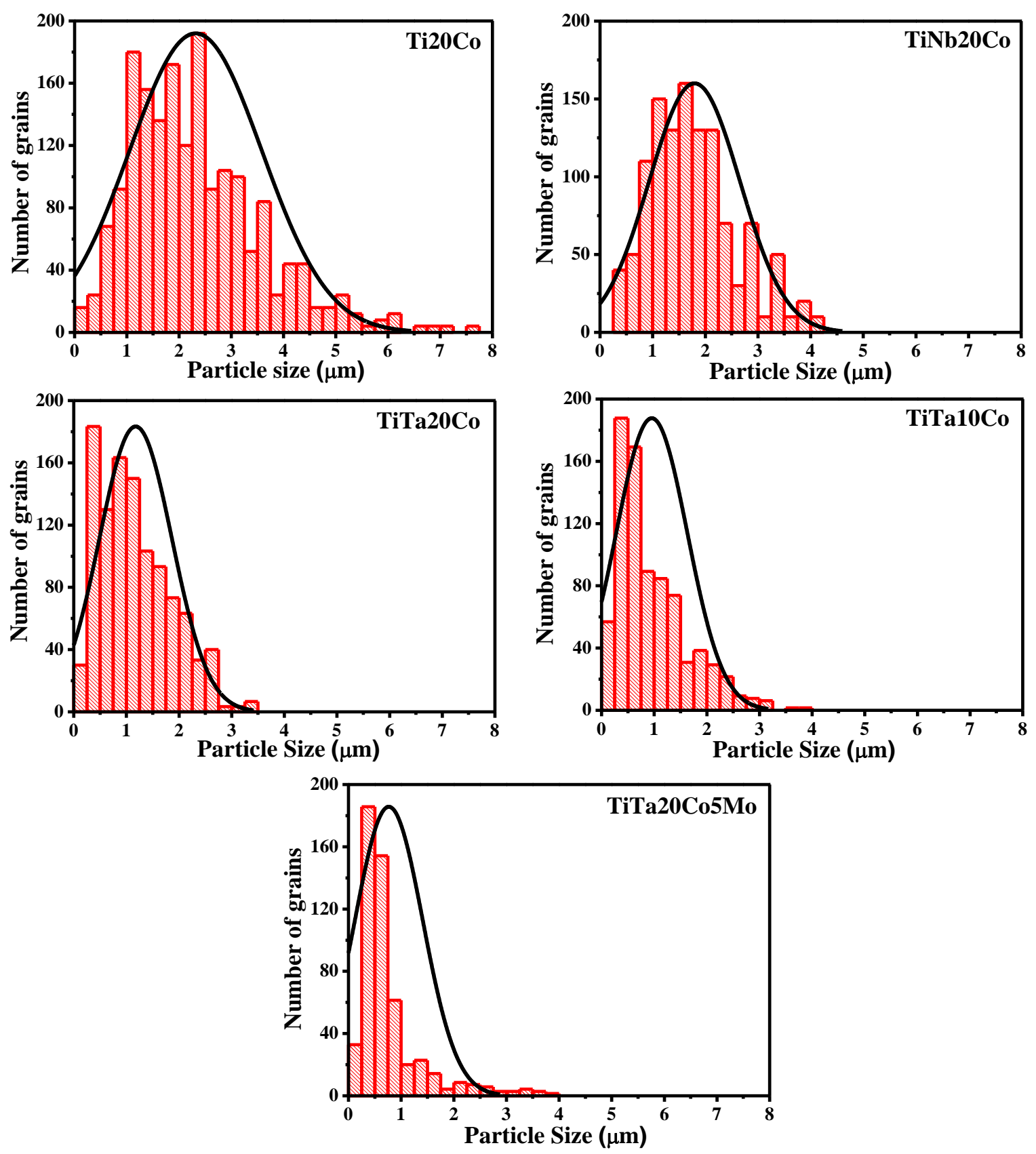

Figure 4 


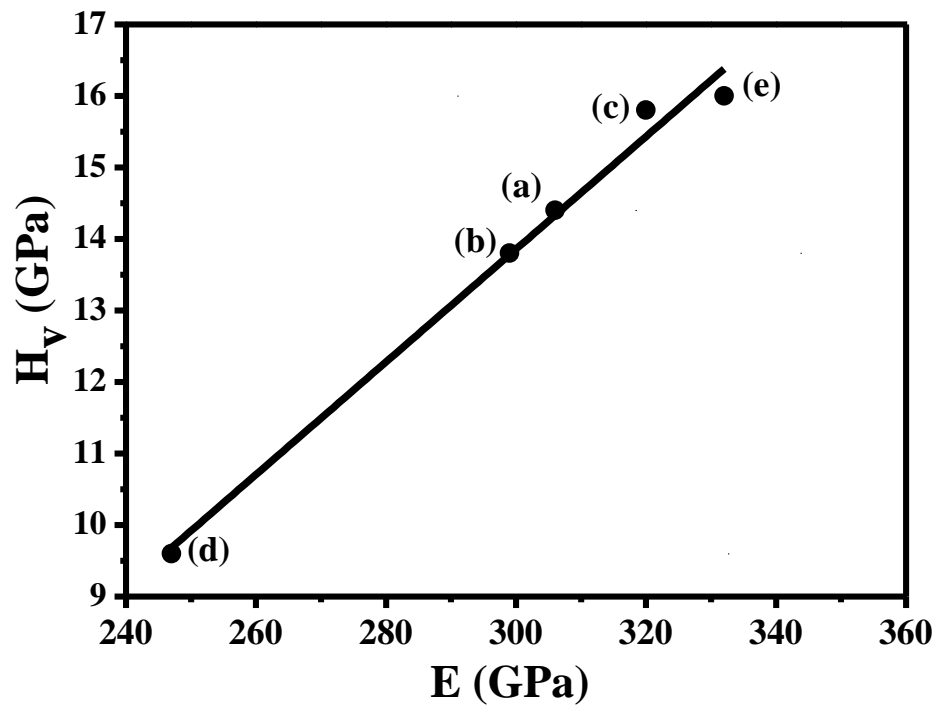

Figure 5 


\section{Ti20Co (C)}

\section{Ti20Co (B)}

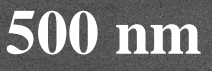

$500 \mathrm{~nm}$

TiNb20Co (C)

$500 \mathrm{~nm}$

TiNb20Co (B)

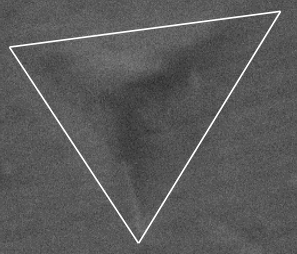

r.

$500 \mathrm{~nm}$

TiTa20Co (C)

TiTa20Co (B)

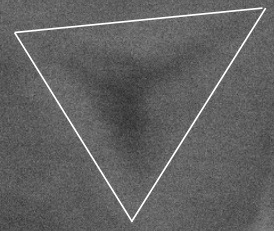

$500 \mathrm{~nm}$ 


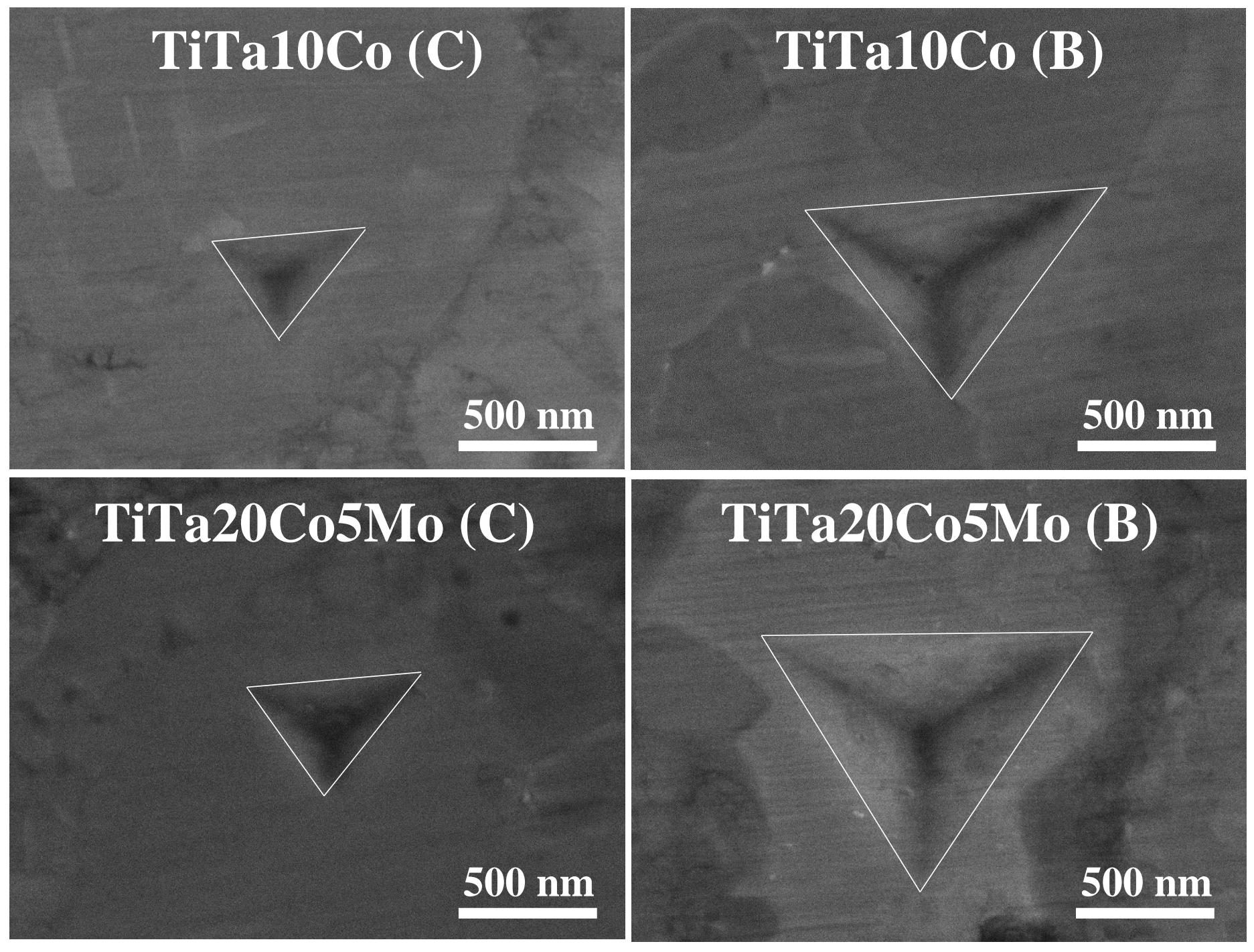

Figure 7 

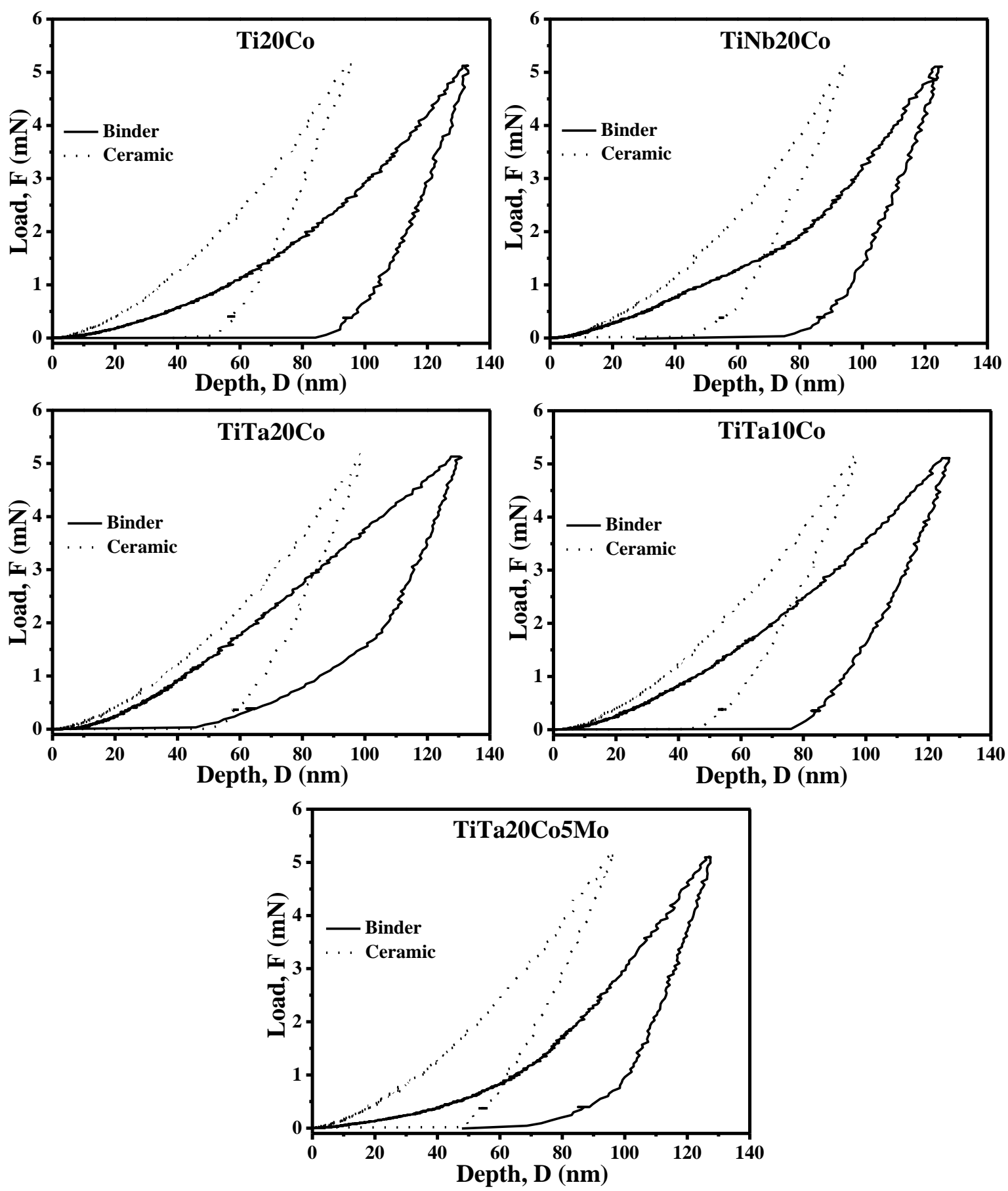

Figure 8 